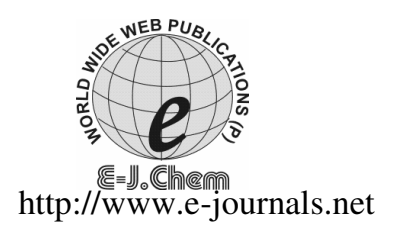

ISSN: 0973-4945; CODEN ECJHAO

E-Journal of Chemistry

2011, 8(1), 77-84

\title{
Effect of Anionic Surfactant on the Thermo Acoustical Properties of Sodium Dodecyl Sulphate in Polyvinyl Alcohol Solution by Ultrasonic Method
}

\author{
S.RAVICHANDRAN ${ }^{*}$ and C.RATHIKA THAYA KUMARI \\ *Department of Physics \\ Sathyabama University, Chennai-600 119.Tamilnadu, India \\ Department of physics, \\ Alagappa University, Karaikudi, Tamilnadu, India. \\ rs_ravichandran@yahoo.com
}

Received 23 April 2010; Accepted 17 June 2010

\begin{abstract}
The interaction of sodium dodecyl sulphate (SDS) / poly(vinyl alcohol) (PVA) solution was studied by ultrasonic velocity measurements. Ultrasonic velocity, density, viscosity in mixtures of sodium dodecyl sulphate in polyvinyl alcohol was measured over the entire range of composition. From the experimental data, other related thermodynamic parameters, viz., adiabatic compressibility, intermolecular free length, surface tension, relative association, relaxation time, absorption coefficient and internal pressure were calculated. Formations of rods interfere with velocity of ultrasonic waves. Hence the ultrasonic velocity decreases with concentration. These results were interpreted in terms of polymer-surfactant complex reactions.
\end{abstract}

Keywords: Sodium dodecyl sulphate, Polyvinyl alcohol, Ultrasonic velocity, Viscosity, Acoustical parameters.

\section{Introduction}

Water-soluble polymers have been shown to interact with surfactant species to varying degrees, depending on the properties of the polymers and surfactants. Surfactants and watersoluble polymers have very broad ranges of applications. Polyvinyl alcohol has variety of applications. It is used as protective colloid, for aqueous emulsion. It is also used in wet strength adhesives. Polyvinyl alcohol fibers have excellent dimensional stability. Anionic surfactants interact with neutral polymer more readily than cationic surfactant. The combined occurrence of polymers and surfactants is found in such diverse products as cosmetics, paints, detergents, foods, polymer synthetics and formulations of drugs and pesticides. The presence of a nonionic polymer in aqueous solutions of ionic surfactants 
causes changes in the physical properties of the micelle aggregates formed by the surfactant ${ }^{1-2}$. Some possible types of association involving either individual surfactant molecule or surfactant cluster were discussed by Nagarajan and Kalpaki ${ }^{3}$. The system sodium dodecyl sulphate (SDS)-poly(vinyl alcohol) has been studied mainly by the classical methods ${ }^{4-6}$. Surfactant-polymer interactions involve various modes of association due to dipole-dipole or ion-ion forces.

Kim Gracie $^{7}$ studied the thermodynamic properties of micellization of sodium dodecyl sulphate in binary mixtures of ethylene glycol with water. Mingtan Hal and Buxing Han ${ }^{8}$ have studied the interaction between the SDS and polyacrylamide binary mixtures. When both the surfactant and the polymer are charged, the interactions are dominated by strong Coulombic forces. Solubility of the polymer is, however, possible at lower concentrations of the surfactant. In this work, we have focused our attention on ultrasonic behaviour and other thermo dynamical properties of binary solution of sodium dodecyl sulphate in poly vinyl alcohol in different concentrations at $303 \mathrm{~K}$.

\section{Experimental}

Sodium dodecyl sulphate (Sigma-Aldrich Co.) of molecular weight of $288.38 \mathrm{~g} / \mathrm{mol}$ were dissolved in water for analysis. Polyvinyl alcohol (PVA) (Extra Pure, Sd Fine Chemicals) AR grade with a molecular weight of 1, 25,000 were dissolved in water and the solution were prepared at different concentrations. SDS was mixed with polyvinyl alcohol solution in different concentrations and ultrasonic velocity studies were reported. Doubly distilled water was used in all cases. Ultrasonic interferometer of fixed frequency (2MHz) (Mittel Enterprises, New Delhi) was used to measure the ultrasonic velocity. An Ostwald's viscometer was used to measure the viscosity of the solution. A $25 \mathrm{~mL}$ of gravity bottle was used to measure the density of the solution and are accurate to three decimal places.

\section{Results and Discussion}

In polymer/surfactant complexation, it is well established that three different forces are involved in the associations. In the case of nonionic polymers/ionic surfactants, polymersurfactant interactions are driven mainly by their hydrophobic ${ }^{9-10}$ through the reduction of the hydrocarbon/water contact area of the polymer and surfactant hydrophobic segments. Another type of force promotes the complex associations through dipole-ion interactions ${ }^{11-13}$. The third type is the strong columbic or charge-charge interaction between oppositely charged species ${ }^{14-15}$. In pure PVA, molecules are associated through intermolecular hydrogen bonds. In the present study, author expected the reaction of anionic surfactant SDS through either hydrophobic group interaction or hydrophilic group interaction or both, due to the nonionic/cationic nature of polymer. By using Ultrasonic velocity and density, various acoustical parameters like acoustic impedance $(\mathrm{Z})$, intermolecular free length $\left(\mathrm{L}_{\mathrm{f}}\right)$, adiabatic compressibility $\left(\beta_{\mathrm{ad}}\right)$ were calculated using the usual relations ${ }^{16}$.

Experimental data on ultrasonic velocity, density, viscosity and other acoustical properties of $0.25 \mathrm{~N}$ of SDS in polyvinyl alcohol solutions at $303 \mathrm{~K}$ were reported in Tables $1 \& 2$. The variations of ultrasonic velocity were found increased with mole fraction of SDS. The variations of relative viscosity were found linear. The variations in viscosity were due to the structural changes ${ }^{17}$. Variation in ultrasonic velocity in any solution generally indicates molecular association in it. This is due to the interaction between solutesolvent molecules. Interaction is weaker at minimum velocity ${ }^{16}$. 
Table 1. Experimental values of ultrasonic velocity $(U)$, density $(\rho)$, viscosity $(\eta)$, adiabatic compressibility $\left(\beta_{\mathrm{ad}}\right)$, acoustic impedance $(Z)$ and relative association $\left(\mathrm{R}_{\mathrm{A}}\right)$ of sodium dodecyl sulphate (SDS) $(0.25 \mathrm{~N})$ in poly (vinyl alcohol) solution at $303 \mathrm{~K}$

\begin{tabular}{|c|c|c|c|c|c|c|}
\hline 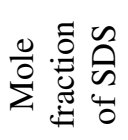 & 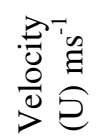 & 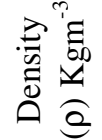 & 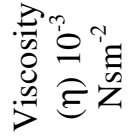 & $\begin{array}{c}\text { Adiabatic } \\
\text { Compressibility } \\
\left(\beta_{\mathrm{ad}}\right) 10^{-10} \mathrm{Kg}^{-1} \mathrm{~ms}^{2}\end{array}$ & $\begin{array}{c}\text { Acoustic } \\
\text { Impedance } \\
\text { (Z) } 10^{6} \mathrm{Kgm}^{-2} \mathrm{~s}^{-1}\end{array}$ & $\begin{array}{c}\text { Relative } \\
\text { association } \\
\left(\mathrm{R}_{\mathrm{A}}\right)\end{array}$ \\
\hline 0 & 1534 & 1064 & 4.640 & 3.992 & 1.632 & 1.000 \\
\hline 0.9943 & 1536 & 1072 & 4.865 & 3.953 & 1.646 & 1.011 \\
\hline 0.9974 & 1532 & 1077 & 5.190 & 3.956 & 1.649 & 1.007 \\
\hline 0.9985 & 1537 & 1081 & 5.877 & 3.917 & 1.660 & 1.021 \\
\hline 0.9990 & 1537 & 1083 & 5.978 & 3.907 & 1.664 & 1.023 \\
\hline 0.9994 & 1540 & 1088 & 6.223 & 3.875 & 1.675 & 1.034 \\
\hline 0.9996 & 1541 & 1095 & 6.501 & 3.848 & 1.686 & 1.041 \\
\hline 0.9997 & 1538 & 1098 & 6.808 & 3.849 & 1.688 & 1.039 \\
\hline 0.9998 & 1535 & 1101 & 6.957 & 3.856 & 1.689 & 1.035 \\
\hline 0.9999 & 1536 & 1103 & 7.122 & 3.845 & 1.693 & 1.039 \\
\hline 1.0000 & 1522 & 1106 & 7.209 & 3.905 & 1.682 & 1.014 \\
\hline
\end{tabular}

Table 2. Experimental values of surface tension $(\sigma)$, free length $\left(\mathrm{L}_{\mathrm{f}}\right)$, relaxation time $(\tau)$, absorption coefficient $\left(\alpha / \mathrm{f}^{2}\right)$ and internal pressure $\left(\Pi_{\mathrm{i}}\right)$ of sodium dodecyl sulphate (SDS) $(0.25 \mathrm{~N})$ in poly(vinyl alcohol) solution at $303 \mathrm{~K}$.

\begin{tabular}{|c|c|c|c|c|c|}
\hline $\begin{array}{l}\text { Mole } \\
\text { fraction } \\
\text { of SDS }\end{array}$ & 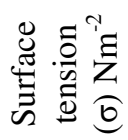 & $\begin{array}{l}\text { Molecular } \\
\text { free length } \\
\left(\mathrm{L}_{\mathrm{f}}\right) 10^{-11} \mathrm{~m}\end{array}$ & $\begin{array}{l}\text { Relaxation } \\
\text { time }(\tau) \\
10^{-12} \mathrm{sec}\end{array}$ & $\begin{array}{c}\text { Classical } \\
\text { Absorption }\left(\alpha / \mathrm{f}^{2}\right)_{\text {class }} \\
10^{-11} \mathrm{NPS}^{2} \mathrm{~m}^{-1}\end{array}$ & 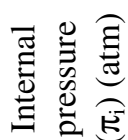 \\
\hline 0 & 40289 & 4.1461 & 2.4704 & 3.176 & 0.00149 \\
\hline 0.9943 & 40653 & 4.1259 & 2.5648 & 3.292 & 0.00226 \\
\hline 0.9974 & 40678 & 4.1275 & 2.7382 & 3.525 & 0.00335 \\
\hline 0.9985 & 41019 & 4.1070 & 3.0703 & 3.939 & 0.00501 \\
\hline 0.9990 & 41123 & 4.1017 & 3.1149 & 3.996 & 0.00708 \\
\hline 0.9994 & 41428 & 4.0847 & 3.2158 & 4.176 & 0.01027 \\
\hline 0.9996 & 41701 & 4.0708 & 3.3363 & 4.270 & 0.01542 \\
\hline 0.9997 & 41731 & 4.0711 & 3.4943 & 4.480 & 0.02458 \\
\hline 0.9998 & 41696 & 4.0751 & 3.5781 & 4.598 & 0.04369 \\
\hline 0.9999 & 41802 & 4.0692 & 3.6524 & 4.690 & 0.10416 \\
\hline 1.0000 & 41352 & 4.1006 & 3.7539 & 4.865 & 2.27886 \\
\hline
\end{tabular}

An anionic surfactant, SDS acts an emulsifier. Polyvinyl alcohol is used as a suspension stabilizer to prevent coalescence which occurs during the polymerization. In general, in any solution containing surfactant, changes in physicochemical properties of solution relate to the changes in surfactant concentration. The ultrasonic velocity, density and viscosity and other acoustical parameters of $0.5 \mathrm{~N}$ of SDS in PVA solution at $303 \mathrm{~K}$ are reported in Tables $3 \& 4$. The variation of ultrasonic velocity was found to be non-linear. The decreasing minimum velocity of ultrasonic velocity indicates the weakening of molecular association at a mole fraction of 0.9997 of $\operatorname{SDS}^{16}$. Density increases with concentration of SDS in PVA solution. This may be interpreted to the structure of the solvent due to the added solute. In the lower region of SDS, the linear change of velocity indicates the miscibility of the solution. 
Table 3. Experimental values of ultrasonic velocity $(U)$, density $(\rho)$, viscosity $(\eta)$, adiabatic compressibility $\left(\beta_{\mathrm{ad}}\right)$, acoustic impedance $(\mathrm{Z})$ and relative association $\left(\mathrm{R}_{\mathrm{A}}\right)$ of sodium dodecyl sulphate (SDS) $(0.5 \mathrm{~N})$ in poly (vinyl alcohol) solution at $303 \mathrm{~K}$

\begin{tabular}{|c|c|c|c|c|c|c|}
\hline $\begin{array}{l}\text { Mole } \\
\text { fraction } \\
\text { of SDS }\end{array}$ & $\begin{array}{l}\overbrace{0}^{\top} \tilde{y} \\
\frac{0}{0} \\
>\end{array}$ & 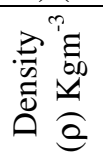 & 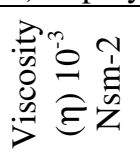 & $\begin{array}{c}\text { Adiabatic } \\
\text { Compressibility } \\
\left(\beta_{\mathrm{ad}}\right) 10^{-10} \mathrm{Kg}^{-1} \mathrm{~ms}^{2}\end{array}$ & $\begin{array}{c}\text { Acoustic } \\
\text { Impedance } \\
\text { (Z) } 10^{6} \mathrm{Kgm}^{-2} \mathrm{~s}^{-1}\end{array}$ & $\begin{array}{l}\text { Relative } \\
\text { association } \\
\quad\left(\mathrm{R}_{\mathrm{A}}\right)\end{array}$ \\
\hline 0.0000 & 1534 & 1091 & 5.629 & 3.894 & 1.673 & 1.000 \\
\hline 0.9971 & 1506 & 1095 & 5.873 & 4.025 & 1.649 & 0.950 \\
\hline 0.9987 & 1531 & 1096 & 6.401 & 3.890 & 1.678 & 0.999 \\
\hline 0.9993 & 1540 & 1098 & 7.010 & 3.840 & 1.690 & 1.017 \\
\hline 0.9995 & 1532 & 1098 & 7.137 & 3.962 & 1.664 & 0.971 \\
\hline 0.9997 & 1525 & 1099 & 7.393 & 4.017 & 1.653 & 0.962 \\
\hline 0.9998 & 1518 & 1102 & 7.538 & 4.091 & 1.648 & 0.959 \\
\hline 0.9999 & 1514 & 1105 & 7.783 & 4.167 & 1.636 & 0.946 \\
\hline 0.9999 & 1511 & 1106 & 8.121 & 4.257 & 1.633 & 0.944 \\
\hline 0.9999 & 1499 & 1113 & 8.397 & 4.298 & 1.628 & 0.941 \\
\hline 1.0000 & 1504 & 1118 & 8.589 & 3.953 & 1.681 & 0.965 \\
\hline
\end{tabular}

Table 4. Experimental values of surface tension $(\sigma)$, free length $\left(\mathrm{L}_{\mathrm{f}}\right)$, relaxation time $(\tau)$, absorption coefficient $\left(\alpha / \mathrm{f}^{2}\right)$ class and internal pressure $\left(\pi_{\mathrm{i}}\right)$ of sodium dodecyl sulphate (SDS) $(0.5 \mathrm{~N})$ in poly (vinyl alcohol) solution at $303 \mathrm{~K}$

\begin{tabular}{cccccc}
\hline $\begin{array}{c}\text { Mole } \\
\text { fraction } \\
\text { of SDS }\end{array}$ & $\begin{array}{c}\text { Surface } \\
\text { tension } \\
(\sigma) \mathrm{Nm}-2\end{array}$ & $\begin{array}{c}\text { Molecular } \\
\text { Free length } \\
\left(\mathrm{L}_{\mathrm{f}}\right) 10^{-11} \mathrm{~m}\end{array}$ & $\begin{array}{c}\text { Relaxation } \\
\text { time }(\tau) \\
10^{-12} \mathrm{sec}\end{array}$ & $\begin{array}{c}\text { Classical } \\
\text { Absorption }\left(\alpha / \mathrm{f}^{2}\right)_{\text {class }} \\
10^{-11} \mathrm{NPS}^{2} \mathrm{~m}^{-1}\end{array}$ & $\begin{array}{c}\text { Internal } \\
\text { pressure } \\
\left(\pi_{\mathrm{i}}\right)(\mathrm{atm})\end{array}$ \\
\hline 0.0000 & 41299 & 4.0951 & 2.9232 & 3.7577 & 5.2719 \\
0.9971 & 40329 & 4.1630 & 3.1523 & 4.1270 & 0.8009 \\
0.9987 & 41376 & 4.0930 & 3.3208 & 4.2761 & 1.2735 \\
0.9993 & 41797 & 4.0666 & 3.5904 & 4.5974 & 1.6043 \\
0.9995 & 40835 & 4.1304 & 3.7709 & 4.9050 & 1.8149 \\
0.9997 & 40424 & 4.1589 & 3.9602 & 5.1888 & 1.9869 \\
0.9998 & 40647 & 4.1594 & 4.0121 & 5.2471 & 2.1074 \\
0.9999 & 40855 & 4.1623 & 4.1176 & 5.3756 & 2.2208 \\
0.9999 & 41746 & 4.1652 & 4.1765 & 5.3980 & 2.3187 \\
0.9999 & 40691 & 4.1694 & 4.4773 & 5.8899 & 2.4452 \\
1.0000 & 41090 & 4.1258 & 4.5280 & 5.9367 & 2.5209 \\
\hline
\end{tabular}

Viscosity of a solution is a measure of cohesiveness or rigidity present in between the ions or ion-solvent or solvent-solvent molecules present in a solution. Viscosity measurements ideally would yield information on the association and conformation of the polymer surfactant complex. Density and viscosity of any solution is directly related to each other. Viscosity is calculated by using the formula and it is related to normal forces in the liquids.

$$
\text { Viscosity }(\eta)=\eta_{w} \rho t / \rho_{w} t_{w} \quad N^{-2}
$$

Where $\eta_{w}, \rho_{w}$ and $t_{w}$ are respectively the viscosity, density and the time of water and $\rho$ and $t$ are respectively the density and time of flow of mixture. Viscosity increases in both cases with concentration and it indicates the increase of cohesiveness present in the solutesolvent molecules ${ }^{18}$. The low viscosity obtained at low concentration, is a reflection of polymer-coiled structure due to the drive towards a minimization of the contact area of its 
hydrophobic segments and it increases due to electroviscus effect. The variations of acoustic impedance $(\mathrm{Z})$ for both cases are shown in Table $1 \&$ Table 3 . Acoustic impedance is the reciprocal of compressibility.

$$
\text { Specific Acoustic impedance }(Z)=U \rho \mathrm{kg} \mathrm{m}^{-2} \mathrm{~S}^{-1}
$$

It is evident that acoustic impedance values increase with increase in concentration of SDS in lower concentration where as it is non-linear in higher concentration of SDS. The increase of impedance values with solute concentration can be attributed to the effective solute-solvent interactions ${ }^{19}$.

The variations of compressibility of binary mixtures of two set of concentration are shown in Tables 1-3. The adiabatic compressibility $\left(\beta_{\mathrm{ad}}\right)$ was calculated from ultrasonic velocity $(\mathrm{U})$ and density $(\rho)$

$$
\beta_{\mathrm{ad}}=\left(\mathrm{U}^{2} \rho\right)^{-1} \mathrm{~kg}^{-1} \mathrm{~m} \mathrm{~S}^{2} \text {. }
$$

Compressibility values decrease up to minimum value as the concentration increases and then increases with increase of concentration and again it decreases. The minimum compressibility indicates the enhancement of bond strength and the maximum compressibility indicates the poor bond strength of the molecules. It decreases with concentration in $0.25 \mathrm{~N}$ and it was found as non-linear in $0.5 \mathrm{~N}$ of SDS solution. However the compressibility value tends to decrease with increase in the concentration of SDS. This can be explained in terms of the electrostatic effects of polymer on the surrounding molecules ${ }^{20}$. The increase in compressibility may be due to departure of solvent molecules around the ions, supporting for weak interactions. The relative association is influenced by two factors.

(1) The breaking up of the solvent molecules on addition of solute to it and

(2) The salvation of solutes those are simultaneously present.

$$
\text { The Relative association } \mathrm{R}_{\mathrm{A}}=\left[\mathrm{d} / \mathrm{d}_{\mathrm{o}}\right]\left[\mathrm{U}_{\mathrm{o}} / \mathrm{U}\right]^{1 / 3}
$$

Where $d_{o}$ and $U_{o}$ are the density and ultrasonic velocity of the solvent and $d$ and $U$ are the density and ultrasonic velocity of solution. The variations of relative association are shown in Tables $1 \& 3$. It increases with concentration in the case of $0.25 \mathrm{~N}$ of SDS. It is maximum at a mole fraction of 0.9996 and it decreases with increasing the concentration. In other cases, it was found non-linear. It is again due to the fact of interactions between the solute and solvent ${ }^{21}$. The intermolecular free length depends upon the adiabatic compressibility and shows a similar to that of compressibility and inverse to the velocity.

$$
\text { Intermolecular free length }\left(\mathrm{L}_{\mathrm{f}}\right)=\mathrm{k}\left(\beta_{\mathrm{ad}}\right)^{1 / 2} \mathrm{~m}
$$

Intermolecular free length depends upon adiabatic compressibility and shows a behavior similar to that of compressibility and inverse to the velocity. The behavior of intermolecular free length is an inverse behavior of sound propagation. Here on increasing the concentration, molecular free length decreases at $0.25 \mathrm{~N}$ of SDS, whereas it was found non-linear variation in the case of higher concentration of SDS. The decrease of molecular free length with concentration indicates that the structural readjustment in the liquid mixture and it suggests the presence of strong solute-solvent interactions with a less compressible phase or closer packing molecules. It increases with the further increase of concentration, indicating the weak interactions between solute-solvent molecules ${ }^{22}$.

Surface tension is a diagnostic parameter for describing various properties of liquids and liquid mixtures. In the present work, surface tension increases with the addition of solvent. The observation is in accordance with the change in mean free length ${ }^{23}$. A sudden 
sharp reduction is most likely due to surface film formation. SDS shows its usual behavior with a CMC at $6 \times 10^{-3} \mathrm{M}$. A greatest reduction occurs at a higher concentration of SDS due to the formation of surface-active complex.

Acoustical relation time is directly proportional to viscosity and it shows a linear variation. Relaxation time values $(\tau)$ for both system of SDS calculated by using viscosity and ultrasonic velocity data, in general, increase with increase in concentration. The values are given in Table 2 and 4. It shows a maximum at higher mole fraction. It is also evident for the interaction between sodium dodecyl sulphate and polyvinyl alcohol solution ${ }^{19,24}$.

The internal pressure is a sensitive parameter to poly-solvent interactions, which reflects both the attractive and repulsive molecular interactions. The internal pressure is an energyvolume coefficient and it is measure of the resultant force of attraction and force of repulsion between the interacting components in the mixture and it is calculated by using the formula

$$
\pi_{\mathrm{I}}=\mathrm{bRT}[\mathrm{K \eta} / \mathrm{U}]^{1 / 2}\left[\rho^{2 / 3} / \mathrm{M}_{\mathrm{eff}}^{7 / 6}\right](\mathrm{atm})
$$

Where ' $\mathrm{b}$ ' is the cubic packing factor which is assumed to be 2 for all the liquids and solutions, ' $K$ ' is the temperature independent constant, ' $R$ ' is the gas constant,' $T$ 'is absolute temperature, ' $\eta$ ' be the viscosity and ' $U$ ' is the ultrasonic velocity and ' $\rho$ ' be the density of the solution.

The increase of internal pressure with concentration also confirms the interaction between the solute-solvent molecules ${ }^{16}$. The studies of ultrasonic absorption in binary mixtures have been undertaken by several investigators. This study leads to an understanding of the mechanism of absorption in each liquid. Classical absorption coefficient $\left(\alpha / \mathrm{f}^{2}\right)$, in general, increase with concentration and it is calculated as per formula ${ }^{22}$. However, if the concentration of SDS is increased, it can be seen that, the classical absorption also increases. This may be due to the fact that the maximum reaction takes place at higher concentration ${ }^{24}$. The results of absorption coefficient as a function of mole fraction show that the transfer of energy (de-excitation of a molecule) is more probable between two different molecules than with molecules of the same species ${ }^{25}$.

Density, ultrasonic velocity and viscosity are measured for the mixture of SDS in Polyvinyl alcohol solution in different concentrations. Density, velocity and viscosity of a solution linearly increase with concentration of at $0.25 \mathrm{~N}$ of Sodium dodecyl sulphate in $2 \%$ of polyvinyl alcohol. It increases up to a mole fraction of 0.9996 and decreases with the further increase of concentration. A sudden decrease of velocity is observed at a mole fraction of 0.9997 and 0.9998 of SDS, since the discontinuity in the sound velocity indicates the critical micelle concentration. At a particular concentration, more ions were introduced in to the solution. The internal pressure is less at the lesser concentration of SDS. As the surfactant concentration increases, the shielding effect (close contact with aggregates) decreases due to the lower polymer-to-surfactant ratios. At lower concentration, the dodecyl Sulphate ions are interacting with poly vinyl alcohol molecules with their hydrophobic and hydrophilic ends towards the medium. In general, at low SDS concentration, the mixtures stay clear. When the amount of SDS is increased, no clear mixtures are observed. However, further addition of SDS may bring the mixtures to their clear state. But at a higher concentration, excess of dodecyl sulphate ions were formed. Increase of the surfactant concentration leads to higher ionic strength, which would influence both the shape and the size of the micellar aggregates. But at a mole fraction of 0.9997 , velocity decreases with increase in molecular free length due to weak interaction in SDS-PVA system. 
An increase in Ultrasonic velocity is observed with increase in the mole fraction of SDS, from 0 to 0.9996 . This variation clearly indicates the complete dissolution of SDS and making the medium more and clearer. The ultrasonic velocity decreases with increase in concentration of SDS, since SDS has got more hydrophilic (sulphate) and hydro phobic (Dodecyl) portions at higher concentrations. The hydrophobic portion may associate to form micelle rods. Formations of such rods interfere with velocity of ultrasonic waves. Hence the ultrasonic velocity decreases with concentration.

In the concentration of $0.5 \mathrm{~N}$ of SDS, the ultrasonic velocity is increases up to the mole fraction of 0.9993 , while above this mole fraction it decreases. Hence, as discussed in the previous case, there must be complete dispersion of SDS up to mole fraction of 0.9993 . The decrease in ultrasonic velocity above this value, might therefore, be attributed to formation of micelle rod and that interfere the propagation of ultrasonic waves. Compare to the results of previous experiment, the maximum in ultrasonic velocity is slight shifted to lower mole fraction of SDS due to high concentration.

\section{Conclusion}

The ultrasonic velocity and other acoustical parameters of sodium dodecyl sulphate in polyvinyl alcohol solution were studied. The variations in the acoustical parameters might be due to the formation of micelle rods in the $0.25 \mathrm{~N}$ of SDS solutions and it indicates the complete dissolution. Ultrasonic velocity was decreased due the formation of micelle rods at higher concentration of SDS in the $0.5 \mathrm{~N}$ concentrations. Hence the formation of rods are depends on the concentration of SDS and it is interacting with polyvinyl alcohol molecules. Further study gives the more information of the formation of micelle rods.

\section{Acknowledgment}

The author is grateful to Dr.P Palanichamy, Professor, Department of Chemistry, Anna University, Chennai, Tamilnadu for his support in this research work. The authors are grateful to Dr. Arumugam, Scientist, Central Leather Research Institute, Chennai, Tamilnadu, Dr.Chandramouleeswaran , Prof:\& Head, Salem, Tamil Nadu, Dr.R.Sampath Kumar, Department of Physics, Sathyabama University, Chennai and Dr.V.Rajendran, Director, Centre for Nano Technology, K.S.R College of Engineering \& Technology, Namakkal District, for encouragement.

\section{References}

1 Haruko Takaya, Susumu Nii, Fumio Kawaizumi and Katsuroku Takahashi, Ultra Sonochem., 2005,12(6), 483-487.

2 Andra Dedinaite, Robert Meszaros, Per M Claesson, J Phys Chem B., 2004, 108, 11645-11653.

$3 \quad$ Nagarajan R and Kalpaki E, NewYork, 1985, 369.

$4 \quad$ Balokhra R L and Nag A, Indian J Pure Appl Phys., 1991, 29, 756.

5 Alessandro D Aprano, Camillo La Mesa and Livio Persi, Langmuir, 1997, 13, 5876-5880.

6 Dubin P L, Chew C H and Gan L M, J Colloid Interface Sci., 1989, 128(2), 566-576.

7 Durai S and Ramadass P, Bull Mater Sci., 2004, 27(1), 57-68.

8 Falguni D Karia and Parsania P H, Eur Polym J., 2000, 36(3), 519-524.

9 Kam C Tam and Evan Wyn-Jonesb, Chem Soc Rev., 2006, 35, 693.

10 Goddard E D and Hannan Plenum R B, New York, 1977, II, 835.

11 John Philip, Jayakumar T, Kalyanasundaram P and Baldev Raj, Phys Rev E, 2002, 66, 1406. 
12 Kalyanama Sundaram S, Sundaresan B and Hemalatha J, J Polym Mater., 2001, 19, 211.

13 Kalyanasundaram S, Manuel Stephan A and Gopalan A, J Polym Mater, 1995, 12, 323.

14 Kim Gracie, Dale Turner, and Palepu R, Can J Chem., 1996, 74, 1616-1625.

15 Lewis K E and Robinson C P, J Colloid Interface Sci., 1970, 32, 539.

16 Mingtran Hai and Buxing Han, J Chem Eng Data, 2006, 51, 1498.

17 Mukerjee P and Mysels K J, National Breau of Standards.Washington D C, 1971.

18 Zhen Zhou, Midan Li and Heliang Yan, Colloids Surf., 2000, 175, 263.

19 Park J W, Lee J G and Lee H, Bull Korean Chem Soc., 1989, 10, 339.

20 Pena L, Junquera E and Aicart E, J Sol Chem., 1995, 24, 1075.

21 Rajagopal K and Jayabalakrishnan S S, J Pure Appl Ultrason., 2006, 28, 81-86.

22 Ravichandran S and Ramanathan K, J Pure Appl Ultrason., 2006, 28, 40.

23 Yadava S S, J Pure Appl Ultrason., 2003, 25,124-129.

24 Sahoo P K, Mohapatra R,.Sahoo A and Swain S K, J Appl Polym Sci., 2003, 88(14), 3196-3201.

25 Syal V K, Anita Chauhan and Suvarcha Chauhan, J Pure Appl Ultrason., 2005, 27, 61-69. 


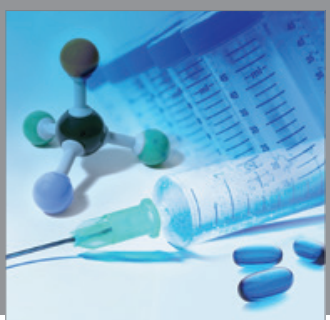

International Journal of

Medicinal Chemistry

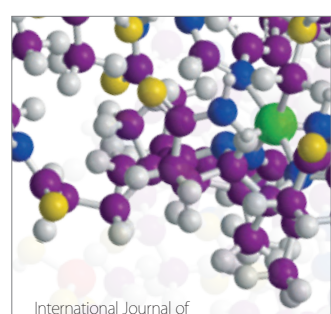

Carbohydrate Chemistry

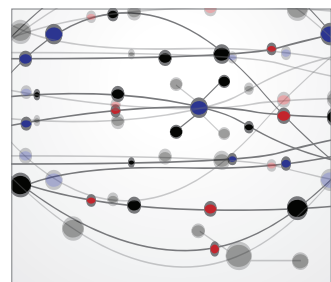

The Scientific World Journal
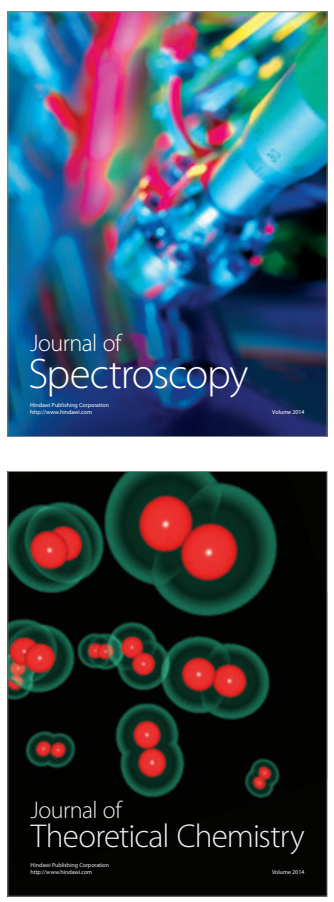
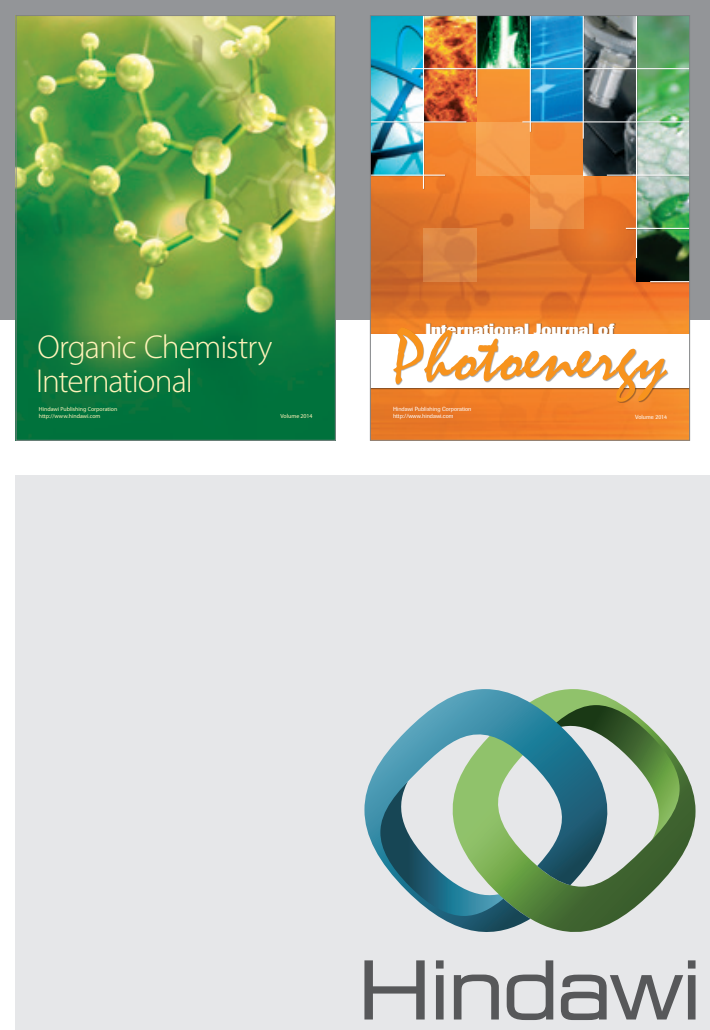

Submit your manuscripts at

http://www.hindawi.com
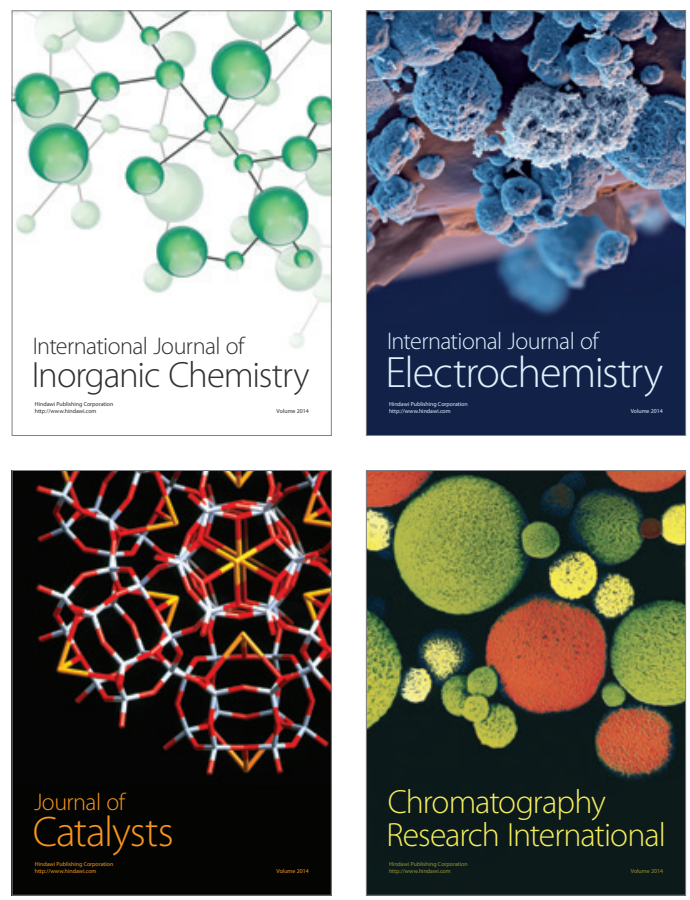
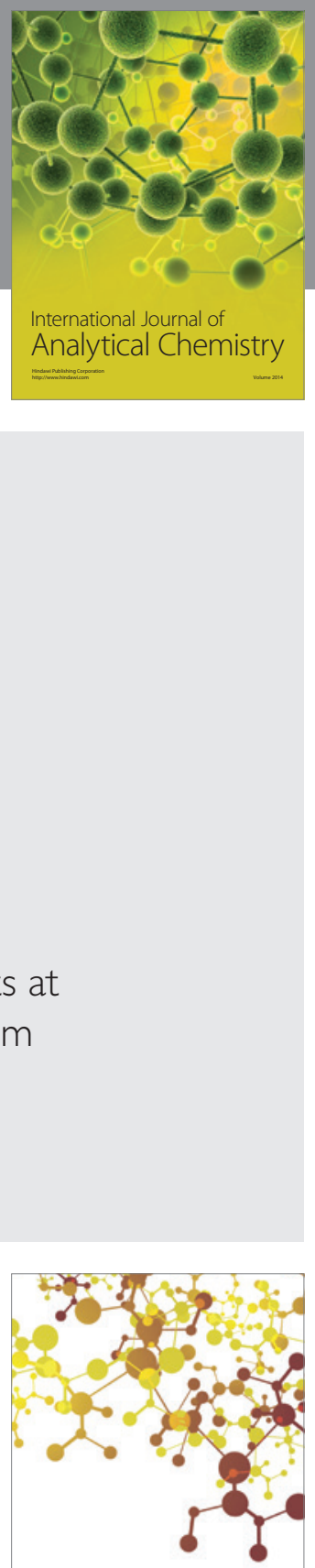

Journal of

Applied Chemistry
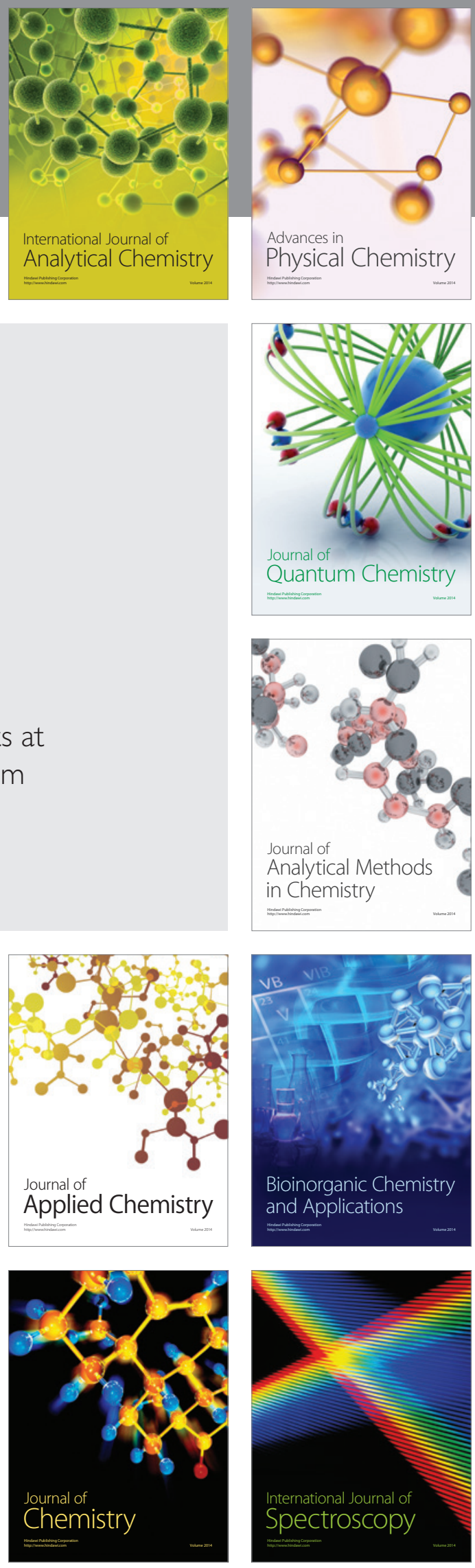